\title{
From Formal Methods to Software Components: Back to the Future?
}

DOI:

10.1007/978-3-319-57666-4_2

\section{Document Version}

Accepted author manuscript

Link to publication record in Manchester Research Explorer

\section{Citation for published version (APA):}

Lau, K-K. (2017). From Formal Methods to Software Components: Back to the Future? In O. Kouchnarenko, \& R. Khosravi (Eds.), Formal aspects of component software : 13th International Conference, FACS 2016, Besancon, France, October 19-21, 2016, revised selected papers (pp. 10-14). (Lecture notes in computer science; Vol. 10231). Springer Nature. https://doi.org/10.1007/978-3-319-57666-4_2

\section{Published in:}

Formal aspects of component software : 13th International Conference, FACS 2016, Besancon, France, October 19-21, 2016, revised selected papers

\section{Citing this paper}

Please note that where the full-text provided on Manchester Research Explorer is the Author Accepted Manuscript or Proof version this may differ from the final Published version. If citing, it is advised that you check and use the publisher's definitive version.

\section{General rights}

Copyright and moral rights for the publications made accessible in the Research Explorer are retained by the authors and/or other copyright owners and it is a condition of accessing publications that users recognise and abide by the legal requirements associated with these rights.

\section{Takedown policy}

If you believe that this document breaches copyright please refer to the University of Manchester's Takedown Procedures [http://man.ac.uk/04Y6Bo] or contact uml.scholarlycommunications@manchester.ac.uk providing relevant details, so we can investigate your claim.

\section{OPEN ACCESS}




\title{
From Formal Methods to Software Components: Back to the Future?
}

\author{
Kung-Kiu Lau \\ School of Computer Science, The University of Manchester \\ Manchester M13 9PL, United Kingdom \\ kung-kiu.lau@manchester.ac.uk
}

\begin{abstract}
Looking back at the past, I believe Formal Methods and Component-based Software Engineering have missed opportunities to synergise. Looking forward to the future, I believe even more strongly that this synergy will be crucial for developing Software Engineering techniques that tackle scale and complexity. In this position paper I outline the fundamentals of my belief, in terms of existing work and future challenges.
\end{abstract}

\section{The Future?}

Any engineering discipline is based on: (i) a well-established underlying theory; (ii) standard parts or components for building systems; and (iii) tools for constructing systems from components, and for verifying systems. So it would seem logical to conclude that Component-based Software Engineering (CBSE) and Formal Methods (FM) are the essential ingredients for Software Engineering.

As software becomes ever more pervasive (witness the Internet of Things), the challenge facing Software Engineering nowadays is how to tackle ever increasing scale and complexity, while guaranteeing safety. Is CBSE + FM up to the challenge? Is CBSE + FM addressing the challenge? To answer in the affirmative, I believe we need to accomplish two things: (i) compositional construction; and (ii) compositional verification.

\section{Compositional Construction}

Compositional construction is what CBSE sets out to achieve. The general picture of CBSE is depicted in Fig. 1. The basic idea is that components should pre-exist, i.e. they should be built independently from specific systems and deposited in a repository. Repository components can be reused in many different systems constructed by composing the components.

Whilst a generic component (Fig. 2(a)) is a unit of composition with provided and required services, commonly used components fall into three main categories: (i) objects (Fig. 2(b)); (ii) architectural units (Fig. 2(c)); and (iii) encapsulated components (Fig. 2(d)). Composition mechanisms (Fig. 3) used by these categories are respectively: (i) direct message passing (method call); (ii) 

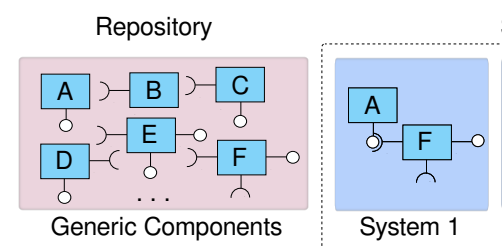

Systems

Fig. 1: CBSE: compositional construction.

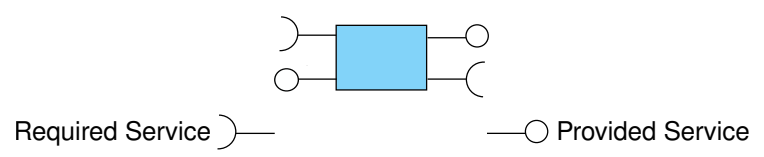

(a) Generic component

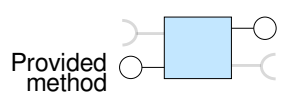

(b) Object

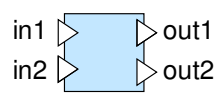

(c) Architectural unit

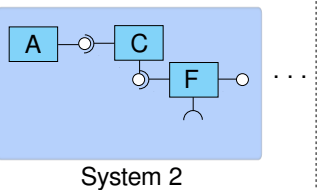

Fig. 2: Types of components.

indirect message passing (port connection); (iii) coordination (exogenous composition).

\begin{tabular}{|c|c|c|c|}
\hline Components & $\begin{array}{c}\text { Provided } \\
\text { services }\end{array}$ & $\begin{array}{c}\text { Required } \\
\text { services }\end{array}$ & $\begin{array}{c}\text { Composition } \\
\text { mechanism }\end{array}$ \\
\hline Objects & Methods & - & Method call \\
\hline $\begin{array}{c}\text { Architectural } \\
\text { units }\end{array}$ & Out-ports & In-ports & $\begin{array}{c}\text { Port } \\
\text { connection }\end{array}$ \\
\hline $\begin{array}{c}\text { Encapsulated } \\
\text { components }\end{array}$ & Methods & None & $\begin{array}{c}\text { Exogenonous } \\
\text { composition }\end{array}$ \\
\hline
\end{tabular}

Fig. 3: Composition mechanisms.

The desiderata for compositional construction are embodied in the idealised component life cycle [1], illustrated in Fig. 4. Apart from the use of pre-existing components from a repository, the key desiderata include composition in both the

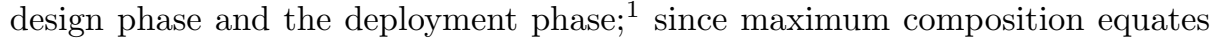
to maximum reuse.

\subsection{Component Models}

For compositional construction, components and their composition mechanisms [5] have to be defined properly. We advocate to do so in a component model $[9,10]$. Fig. 5 shows a taxonomy of current component models with respect to the idealised component life cycle. Categories 1-4 do not support composition in both design and deployment phases. Category 5 does, but has only a lone

${ }^{1}$ Run-time composition, or dynamic reconfiguration, is also meaningful, though it may be harder to define, implement and verify. 


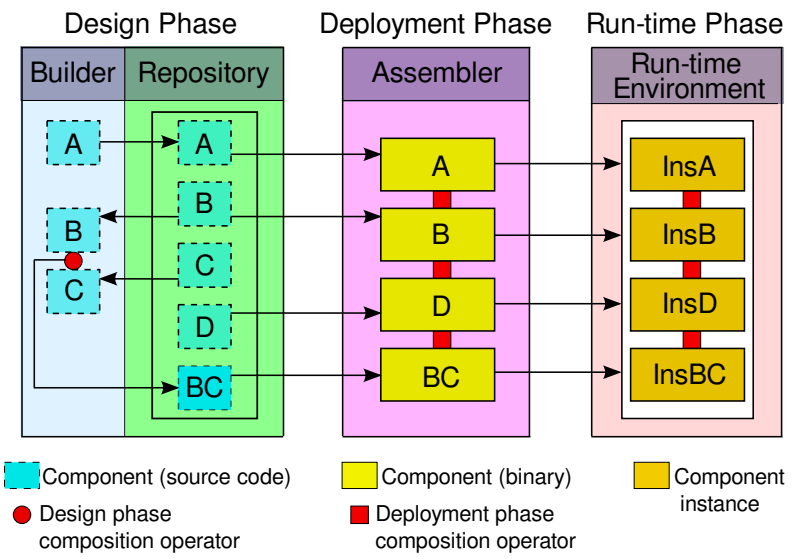

Fig. 4: Idealised component life cycle.

member, namely X-MAN $[8,12,7,2]$, that we have defined and implemented. $\mathrm{X}-\mathrm{MAN}$ achieves compositional construction, but it currently lacks tool support for compositional verification [3].

\section{Compositional Verification}

With compositional construction, we should be able to accomplish compositional verification, i.e. hierarchical, bottom-up, verification of component-based systems whereby the smallest (atomic) components at the lowest level are verified first, and their verification is reused, i.e. not repeated, in the verification of a composite at the next level up.

This is illustrated in Fig. 6, which shows the $\mathrm{W}$ model [6] for componentbased development life cycles: component life cycle and system life cycle, and how they intersect. The $\mathrm{W}$ model supports compositional verification. Component verification is done in the component life cycle when components are developed for the repository, independent of specific systems. Compositional verification is done when a specific system has been assembled from already verified repository components. By reusing the verification of sub-components at successive levels of composition, instead of verifying the complete system as a monolith, compositional verification should be able to scale to large complex systems which are beyond the capability of current verification techniques and tools.

\section{Back to the Future?}

Looking back, I advocated synergy between FM and CBSE [4] at the early stages of the International CBSE Symposium. In my opinion, hitherto this synergy has not really materialised, or at least what little there is has not been effective. I advocated synergy between FM and CBSE [4] According to [11], there has been 

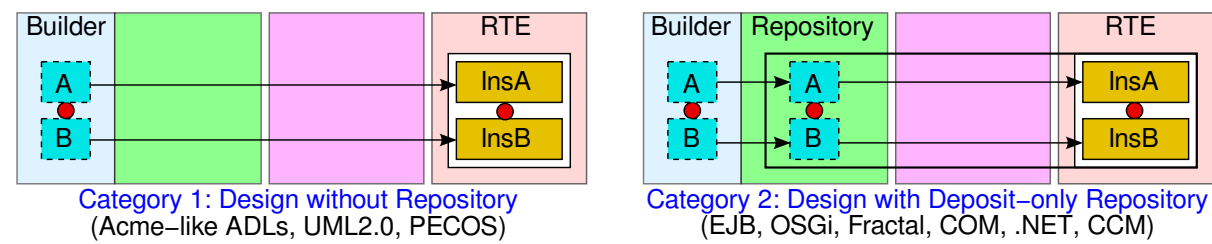

Category 2: Design with Deposit-only Repository

(EJB, OSGi, Fractal, COM, .NET, CCM)
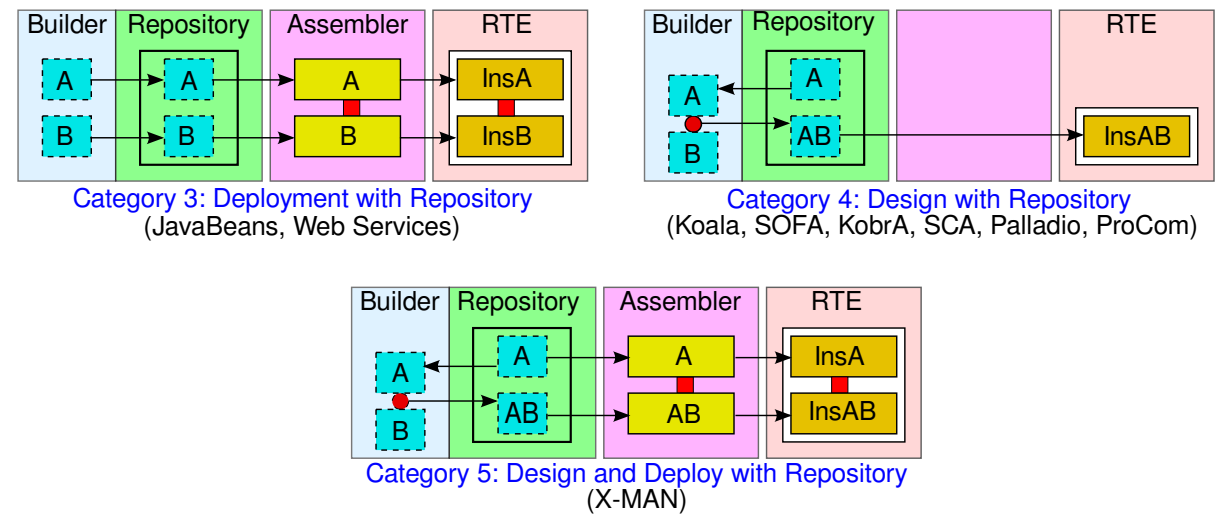

Fig. 5: Idealised component life cycle: taxonomy of component models.

little FM activity at the CBSE symposium. I surmise the converse is true of CBSE activity at FM conferences - maybe even FACS?

Looking forward to the future, I strongly believe that this synergy will be crucial for developing Software Engineering techniques that are not only truly engineering techniques as in traditional engineering disciplines, but can also tackle scale and complexity. In other words, this synergy can provide not only an engineering (compositional) approach to software construction from standard parts, but also compositional reasoning, which together can tackle ever increasing scale and complexity in software systems and their V\&V.

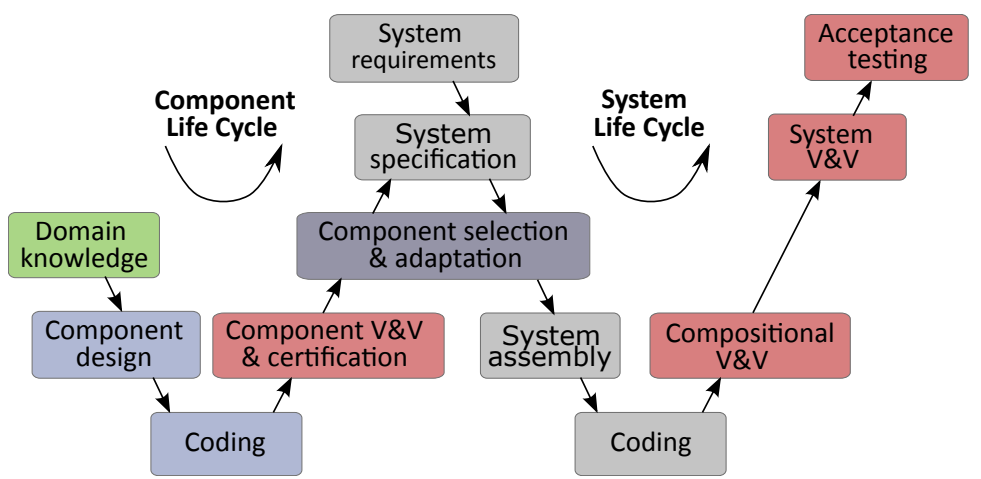

Fig. 6: The W model. 


\section{References}

1. M. Broy, A. Deimel, J. Henn, K. Koskimies, F. Plasil, G. Pomberger, W. Pree, M. Stal, and C. Szyperski. What characterizes a software component? Software Concepts and Tools, 19(1):49-56, 1998.

2. S. Di Cola, C. Tran, and K.-K. Lau. A graphical tool for model-driven development using components and services. In Proceedings of 41 st Euromicro Conference on Software Engineering and Advanced Applications (SEAA) 2015, pages 181-182, 2015.

3. N. He, D. Kroening, T. Wahl, K.-K. Lau, F. Taweel, C. Tran, P. Rümmer, and S. Sharma. Component-based design and verification in X-MAN. In Proc. Embedded Real Time Software and Systems, 2012.

4. K.-K. Lau. Component certification and system prediction: Is there a role for formality? In I. Crnkovic, H. Schmidt, J. Stafford, and K. Wallnau, editors, Proceedings of the Fourth ICSE Workshop on Component-based Software Engineering, pages 80-83. IEEE Computer Society Press, 2001.

5. K.-K. Lau and T. Rana. A taxonomy of software composition mechanisms. In Proc. 36th EUROMICRO Conference on Software Engineering and Advanced Applications, pages 102-110. IEEE, 2010.

6. K.-K. Lau, F. Taweel, and C. Tran. The W Model for component-based software development. In Proc. 37th EUROMICRO Conference on Software Engineering and Advanced Applications, pages 47-50. IEEE, 2011.

7. K.-K. Lau and C. Tran. X-MAN: An MDE tool for component-based system development. In Proc. 38th EUROMICRO Conference on Software Engineering and Advanced Applications, pages 158-165. IEEE, 2012.

8. K.-K. Lau, P. Velasco Elizondo, and Z. Wang. Exogenous connectors for software components. In G.T. Heineman et al., editor, Proc. 8th Int. Symp. on Componentbased Software Engineering, LNCS 3489, pages 90-106. Springer-Verlag, 2005.

9. K.-K. Lau and Z. Wang. Software component models. IEEE Transactions on Software Engineering, 33(10):709-724, October 2007.

10. K.-K. Lau, Z. Wang, S. di Cola, C. Tran, and V. Christou. Software Component Models: Past, Present and Future, 2014. Tutorial at COMPARCH 2014 Conference, 30 June 2014, Lille, France. http://www.cs.man.ac.uk/ kung-kiu/pub/ cbse14tut-slides.pdf.

11. J. Maras, L. Lednicki, and I. Crnkovic. 15 years of CBSE Symposium - impact on the research community. In Proceedings of the 15th International ACM SIGSOFT Symposium on Component-Based Software Engineering, pages 61-70. ACM, 2012.

12. P. Velasco Elizondo and K.-K. Lau. A catalogue of component connectors to support development with reuse. The Journal of Systems and Software, 83:1165$1178,2010$. 